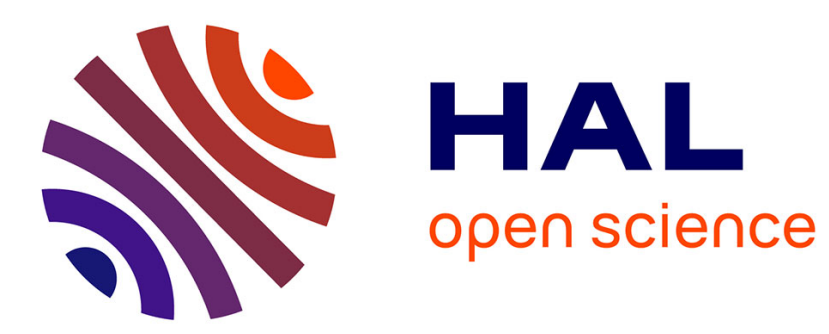

\title{
Race and the Psychological Health of African Americans
}

\author{
Leslie Ashburn-Nardo, Margo J. Monteith, Steven A. Arthur, Amber Bain
}

\section{To cite this version:}

Leslie Ashburn-Nardo, Margo J. Monteith, Steven A. Arthur, Amber Bain. Race and the Psychological Health of African Americans. Group Processes and Intergroup Relations, 2007, 10 (4), pp.471-491. 10.1177/1368430207081536 . hal-00571663

\section{HAL Id: hal-00571663 https://hal.science/hal-00571663}

Submitted on 1 Mar 2011

HAL is a multi-disciplinary open access archive for the deposit and dissemination of scientific research documents, whether they are published or not. The documents may come from teaching and research institutions in France or abroad, or from public or private research centers.
L'archive ouverte pluridisciplinaire HAL, est destinée au dépôt et à la diffusion de documents scientifiques de niveau recherche, publiés ou non, émanant des établissements d'enseignement et de recherche français ou étrangers, des laboratoires publics ou privés. 


\title{
Race and the Psychological Health of African Americans
}

\author{
Leslie Ashburn-Nardo \\ Indiana University - Purdue University Indianapolis
}

\author{
Margo J. Monteith and Steven A. Arthur \\ Purdue University
}

Amber Bain

Northwestern University

\begin{abstract}
This study examined an array of race-related factors pertaining to psychological well-being and distress among 300 African American participants. Findings obtained via structural equation modeling pointed to the importance of having positive implicit ingroup attitudes for psychological health and underscored the significance of Black cultural immersion, particularly in shaping implicit attitudes. Support was obtained for three models: ingroup identity as an antecedent to perceived prejudice, which, in turn, was negatively associated with psychological health; ingroup identity as a consequence of perceived prejudice with positive implications for psychological health; and ingroup identity as a moderator of perceived prejudice, with stronger identity providing a buffer from prejudice. Findings illustrate the consequential and complex role of racial variables in African Americans' psychological health.
\end{abstract}

KEYWORDS implicit racial attitudes, ingroup identity, perceived prejudice, psychological distress, psychological well-being

Social psychologists have long been invested in the study of racial prejudice, from the classic work of Allport (1954) to more recent attempts to understand its subtle, insidious nature (for reviews, see Blair, 2001; Crosby, Bromley, \& Saxe, 1980). Although most of this work has concentrated on the persons who hold prejudiced attitudes, scientists have sounded a special call for more research from the perspective of the targets of prejudice (Graham, 1992; Shelton, 2000; Swim \& Stangor, 1998). Indeed, investigators have increasingly directed their focus on the experience of stigma (for recent reviews, see Major \& O’Brien, 2005;
Major \& Vick, 2005), including its effects on psychological health (e.g., Clark, Anderson, Clark, \& Williams, 1999).

Understanding the psychological ramifications of prejudice is especially important because

\footnotetext{
$\overline{\text { Author's note }}$

Address correspondence to Leslie AshburnNardo, Department of Psychology, Indiana University - Purdue University Indianapolis, 402 North Blackford Street, LD 124, Indianapolis, IN 46202-3275, USA [email: lashburn@iupui.edu]
} 
factors such as psychological well-being are associated with valued outcomes, including increased workplace productivity (Staw, Sutton, \& Pelled, 1994) and greater longevity (Veenhoven, 1988). Although the stigma literature has explored how aspects of psychological health are affected by perceptions of ingroup-directed prejudice and discrimination, there is considerable disagreement about the ways in which stigmarelevant variables relate to each other, which may be due to methodological differences across the studies or may suggest some theoretical gaps. In addition, a shortcoming of the extant stigma literature is its neglect of implicit attitudes for which people have limited conscious awareness. In prejudice research, explicit (i.e., consciously reported) attitudes are often dissociated from implicit attitudes (for reviews, see Blair, 2001; Brauer, Wasel, \& Niedenthal, 2000; Dovidio, Kawakami, \& Beach, 2001) and may contribute uniquely to psychological health.

The goal of the present research was to provide a more comprehensive test of racial constructs as they pertain to the psychological health of African Americans, a group that has historically been a target of much prejudice and discrimination. We assessed the extent of contact our participants reported having with Blacks versus Whites relatively early in life, current implicit racial attitudes, ingroup identity, and perceptions of ingroup-directed prejudice and discrimination, with the goal of determining precisely how these constructs are interrelated and ultimately linked with psychological health. The present investigation is unique in its simultaneous focus on all of these critical constructs, and three other aspects of the research further extend its potential contribution. First, with the use of Structural Equation Modeling (SEM) and latent variables, we moved beyond prior studies by combining previously used measures with additional indicators to yield better estimates of the critical constructs. Second, we tested whether implicit measures offer unique explanatory power, above and beyond selfreported attitudes, in the understanding of stigma and psychological health. Finally, unlike most investigations of stigma, we included both psychological distress and psychological wellbeing variables to determine whether the array of racial constructs that we assessed differentially related to positive (i.e., self-esteem, hope, life satisfaction) versus negative (i.e., depression) health outcomes.

\section{Racial constructs of interest}

\section{Black cultural immersion}

The influence of intergroup contact on racerelated variables has been documented since Allport (1954). More recently, Postmes and Branscombe (2002) found among African Americans that long-term racial segregation (i.e., being surrounded mostly by other Blacks rather than by Whites) was associated with greater identification with and perceived acceptance by the ingroup, which in turn predicted psychological well-being (defined as personal and collective self-esteem). As decades of research on the contact hypothesis have demonstrated, quality of contact is an important factor in intergroup attitudes (for a review, see Pettigrew \& Tropp, 2000). Thus, in the present study we emphasized contact that is driven largely by choice (e.g., friendships) rather than by the fact that African Americans, as a numerical minority, are likely in contact with Whites even in situations in which they have little choice (e.g., in school).

Contact or sociocultural immersion has gained renewed interest in recent years, especially as an important factor in the development of implicit attitudes (Rudman, 2004). For example, Greenwald, McGhee, and Schwartz (1998, Experiment 2) found that the more involvement that Korean-and Japanese-American participants reported in their respective Asian cultures, the stronger their implicit ingroup preference. Likewise, close contact with females (e.g., maternal bonding) has been shown to be important to implicit gender attitudes (Rudman \& Goodwin, 2004), and repeated positive intergroup experiences (e.g., via friends) are critical in conditioning implicit racial attitudes (Aberson, Shoemaker, \& Tomolillo, 2004; Olsson, Ebert, Banaji, \& Phelps, 2005; Rudman, Ashmore, \& Gary, 2001). In the 
present research we were therefore especially interested in the association between Black cultural immersion and participants' implicit racial attitudes, though we tested its relationship with other variables as well.

\section{Implicit racial attitudes}

Although the use of implicit measures to assess social cognitive constructs has become more prevalent in the past 10-15 years (see Fazio \& Olson, 2003, for a review), few studies have investigated the psychological ramifications of implicit attitudes regarding stigmatized ingroups and higher status outgroups. Indeed, in the study of racial prejudice, most of the research employing implicit methodology has focused on Whites' implicit racial attitudes. However, some recent studies have assessed African Americans' implicit racial attitudes. What is most striking about these studies is that Blacks, unlike Whites (e.g., Greenwald et al., 1998, Experiment 3) or even members of artificially created minimal groups (e.g., Ashburn-Nardo, Voils, \& Monteith, 2001), tend not to favor their ingroup implicitly. On average, African American samples have exhibited either a lack of implicit ingroup bias (Livingston, 2002; Nosek, Banaji, \& Greenwald, 2002) or an implicit preference for Whites (Ashburn-Nardo, Knowles, \& Monteith, 2003; Spicer, 1999).

But just how meaningful are such implicit associations? Given the prevalence of environmental stimuli (e.g., in the media) that serve to reinforce more negative associations with Blacks than with Whites (Devine, 1989; Karpinski \& Hilton, 2001), the fact that many African Americans exhibit such attitudes may be of little surprise. Some have even argued that the measure most often used to assess African Americans' implicit racial attitudes, the Implicit Association Test (IAT), reflects culturally acquired, extrapersonal associations and not participants' personal implicit evaluations of the target groups (Olson \& Fazio, 2004).

Perhaps the greatest test of the import of implicit attitudes is their ability to predict meaningful outcomes (Fazio \& Olson, 2003). Few studies have addressed this issue with African American samples, but findings to date suggest that their implicit biases have important implications. For example, Ashburn-Nardo et al. (2003) found that the more Blacks implicitly favored Whites, the greater their preference for a White partner on a task that made stereotypes of intellectual ability salient. Having less positive implicit ingroup attitudes has also been associated with lower implicit self-esteem in African Americans (Ashburn-Nardo, 2004). In the present research, we examined the relationship between African Americans' implicit racial attitudes and their psychological health. Finding that they have implications for either psychological well-being or psychological distress would suggest that Blacks' implicit attitudes do not merely reflect society's characterization of their ingroup but instead have personal significance.

\section{Ingroup identity and perceived prejudice}

One variable that has been repeatedly identified as important to stigmatized persons' psychological health is their ingroup identity, or the degree to which their ingroup is an important part of their self-concept (e.g., Smith \& Henry, 1996; Tropp \& Wright, 2001). For example, classic stage theories of racial identity among African Americans suggest that its evolution is part of the normal course of development and has implications for mental health (e.g., Cross, 1978; Phinney, 1989).

Although most researchers agree that ingroup identity plays an important role in stigmatized persons' psychological welfare, the nature of its role is less clear, especially when identity is considered in relation to perceptions of ingroupdirected prejudice and discrimination. Some studies have found that identity serves as an antecedent to perceived prejudice. For example, Operario and Fiske (2001) found that the stronger minorities' identification with their ingroup, the stronger their reaction to experiences of subtle prejudice. In a longitudinal study, Sellers and Shelton (2003; cf. Eccleston \& Major, 2006) likewise demonstrated a link between strong racial identification and perceptions of ingroup-directed discrimination among African Americans. Furthermore, this research showed that greater perceptions of ingroup-directed 
discrimination were associated with greater psychological distress (defined as anxiety, perceived stress, and depression).

Other findings suggest that identity is enhanced by perceptions of prejudice. For example, McCoy and Major (2003) found that highly identified Latino participants identified even more strongly with their ingroup following exposure to ingroupdirected prejudice. Branscombe and colleagues (Branscombe, Schmitt, \& Harvey, 1999; Postmes \& Branscombe, 2002) also have found that experiencing discrimination and attributing negative outcomes to prejudice were associated with greater ingroup identification. In addition, this research suggested that greater ingroup identification was associated with more positive personal and collective self-esteem in African Americans.

Support has also been found for the moderating role of identity. For example, Eccleston and Major (2006) found that greater perceived prejudice was associated with more severe appraisals of discrimination and, in turn, lower self-esteem only for Latino participants who were low in ingroup identity. Highly identified Latino participants' self-esteem was buffered from perceived prejudice. In contrast, McCoy and Major (2003) found that experiencing prejudice adversely affected self-esteem and depression in women and Latinos only when they strongly identified with their respective ingroups. That is, participants whose ingroups were a significant part of their self-concepts found ingroup threats personally threatening as well. Such inconsistencies suggest that ingroup identity plays a complicated role in the relationship between perceived prejudice and the psychological health of stigmatized persons and thus deserves more empirical attention.

\section{Overview and hypotheses}

A two-year data collection effort provided a sufficiently large sample of African Americans to test models representing the three theoretical perspectives described above: identity as an antecedent of perceived prejudice; identity as a consequence of perceived prejudice; and identity as a moderator of perceived prejudice.
Besides providing a test of convergence with previous research that has investigated the relationships among perceived prejudice and discrimination, ingroup identity, and specifics aspects of psychological health, our inclusion of both psychological well-being and psychological distress allowed us to determine whether the experience of discrimination and ingroupdirected prejudice differentially relates to positive versus negative health outcomes. Moreover, we examined the unique contributions of implicit racial attitudes and a potentially important antecedent, Black cultural immersion. Only by including both proximal and distal factors can models capture more variance in psychological welfare and provide a test of the complex interrelationships among variables.

Figure 1 depicts the identity as antecedent model of psychological health. In this model, ingroup identity was expected to predict greater perceptions of ingroup-directed prejudice (e.g., Eccleston \& Major, 2006; Sellers \& Shelton, 2003), which in turn are associated with less positive well-being and increased distress. Like Eccleston and Major, we also included direct paths from ingroup identity to psychological health, such that stronger identity predicts better psychological health (i.e., greater well-being and less distress). In addition, consistent with previous research, we expected Black cultural immersion to exhibit positive relationships with both implicit racial attitudes and ingroup identity (Greenwald et al., 1998). Most importantly, implicit racial attitudes were hypothesized to predict psychological welfare independently, such that the more participants implicitly favored their ingroup, the more positive psychological wellbeing and the less psychological distress they would report. Indeed, a long history of social identity research (e.g., Tajfel \& Turner, 1986) suggests that favoring one's ingroup is adaptive and psychologically beneficial.

Figure 2 represents the identity as consequence model, which is similar to the previous model except that the directional arrow between ingroup identity and perceived prejudice is reversed. That is, greater perceptions of prejudice may predict increased ingroup identity, which, in 


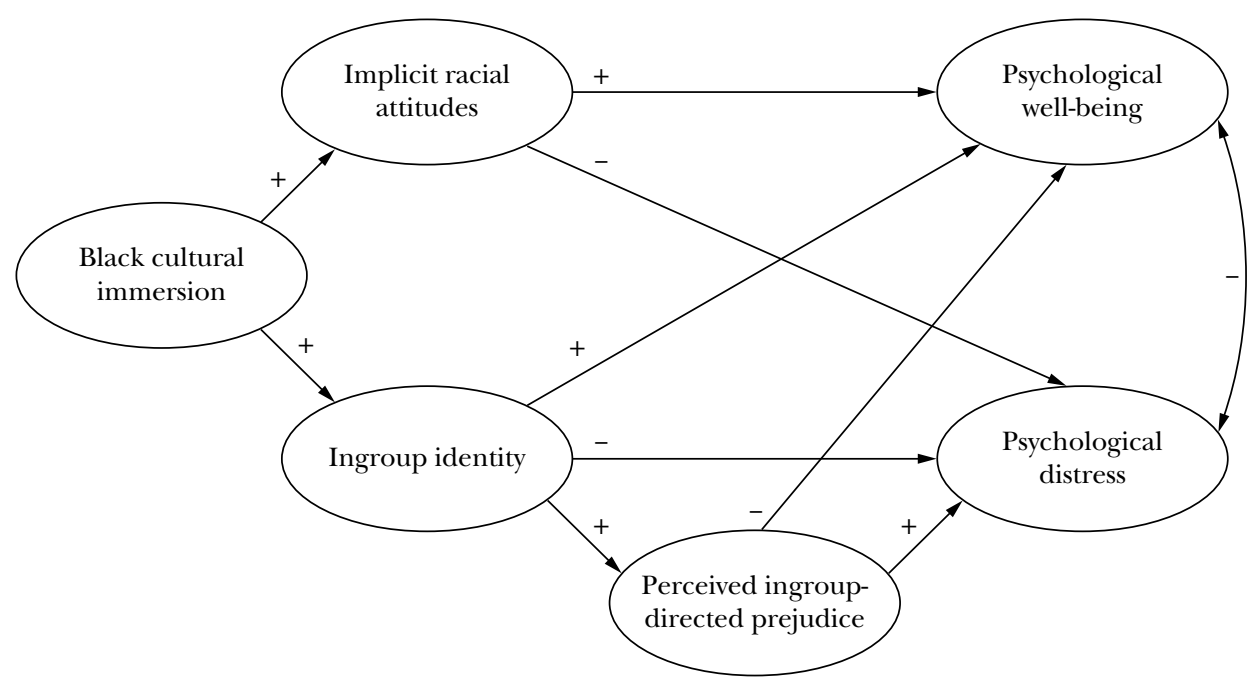

Figure 1. Identity as antecedent model of prejudice and psychological health.

turn, should be associated with enhanced psychological well-being and less psychological distress (e.g., Branscombe et al., 1999; Postmes \& Branscombe, 2002). To be consistent with the conceptually similar identity as resource model tested by Eccleston and Major (2006), we also included direct paths from perceived prejudice to psychological health, such that greater perceptions of prejudice predict worse psychological health (i.e., less positive well-being and increased distress). In addition, like Postmes and Branscombe, we expected Black cultural immersion to exhibit a positive relationship with perceived prejudice, such that the greater the

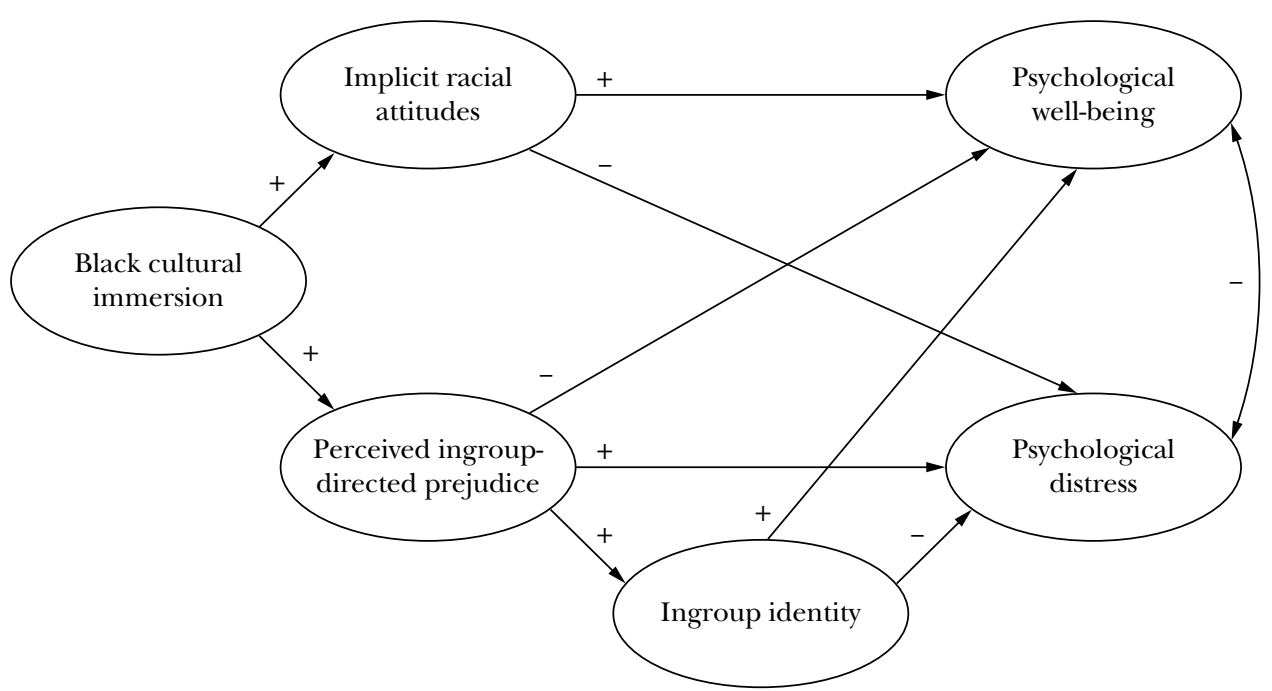

Figure 2. Identity as consequence model of prejudice and psychological health. 
childhood contact with other African Americans, the stronger the perceptions of prejudice or feelings of rejection from Whites.

The identity as moderator model is presented in Figure 3. In this model, the relationships between perceived prejudice and the two psychological outcomes should be moderated by ingroup identity. Given conflicting findings in the extant literature, there are competing hypotheses about the form this interaction should take. One possibility is that positive identity will attenuate the effect of perceived prejudice on psychological health (Eccleston \& Major, 2006), but the other is that it will exacerbate the effects of perceived prejudice (McCoy \& Major, 2003). For the sake of simplicity, we did not include other interactions (e.g., implicit racial attitudes $\times$ ingroup identity) in Figure 3, but they were included in the relevant analysis. In addition, moderator analyses were conducted controlling for Black cultural immersion, as it was assumed to function as an exogenous variable.

\section{Method}

\section{Participants}

Participants were 316 Black undergraduates (226 females, 89 males, 1 did not report gender); all but 7 attended the University of Kentucky. All participants were recruited by phone via lists of potential participants obtained from introductory psychology participant pools or from registrar's lists of Black student enrollment. The majority received US $\$ 15$ as compensation; others earned course credit.

\section{Procedure}

Participants completed the study individually. An experimenter (White for $65 \%$ of the sessions; non-White for $24.3 \%$; data missing for $10.7 \%$ due to recording error) explained that the purpose of the study was to examine the socialization, experiences, and attitudes of African Americans. Participants were then asked to complete the IAT and a packet of self-report questionnaires in counterbalanced order.

IAT Participants were told that the purpose of the IAT was to gain a better understanding of how the mind organizes information about social groups. In fact, the IAT is a computerized dualcategorization task that requires participants to categorize faces as Black versus White and words (e.g., laughter, sickness) as pleasant versus unpleasant as quickly as possible while minimizing mistakes. On critical trials the categorization of faces and words is combined such that participants have to respond, for example, with a key on the left side of the keyboard when the stimulus is a Black face or a pleasant word and with a key on the right side of the keyboard when the stimulus is a White face or an unpleasant word. African American participants who respond faster when the categories Black and

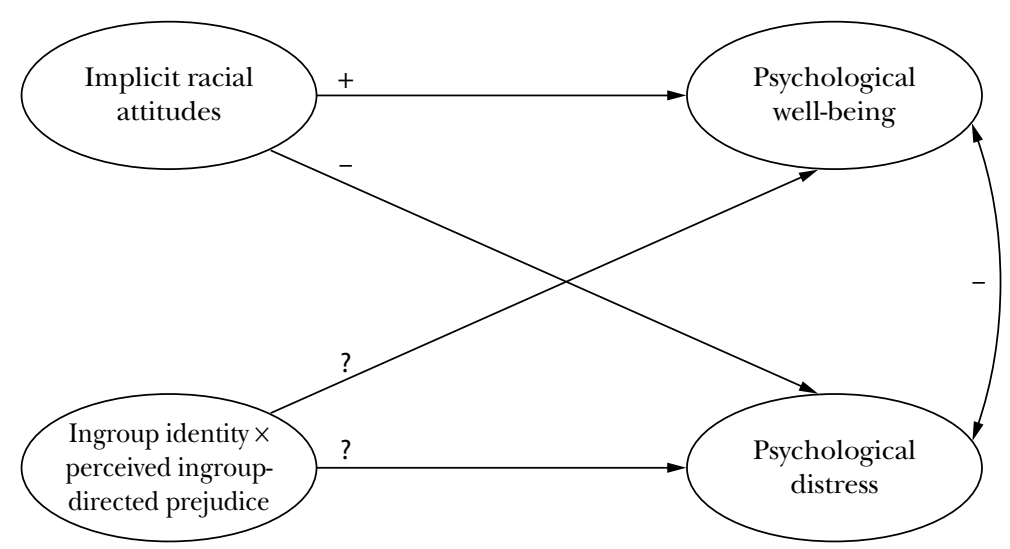

Figure 3. Identity as moderator model of prejudice and psychological health. 
pleasant share one response key and White and unpleasant share the other response key than when the reverse pairings occur exhibit more positive associations with Blacks than with Whites (i.e., ingroup favoritism). Following some general instructions, the experimenter left the room while participants completed a typical racial IAT (e.g., Nosek et al., 2002); Table 1 presents the sequence of trial blocks.

Self-report questionnaires The remaining variables in the study were administered via a packet of randomly ordered questionnaires designed to assess the constructs Black cultural immersion, ingroup identity, perceived ingroupdirected prejudice, psychological well-being, and psychological distress. ${ }^{1}$ The experimenter left the room while participants completed the packet.

The following items were created as indicators of Black cultural immersion. ${ }^{2}$ Each was reported as a percentage; greater values indicate deeper immersion in Black culture.

What percentage of your parents' friends was Black?

While you were growing up, what percentage of your friends was Black?

While you were growing up, what percentage of your close friends was Black?

To assess ingroup identity, participants completed the eight-item racial centrality subscale of the Multidimensional Inventory of Black Identity (MIBI; Sellers, Smith, Shelton, Rowley, \& Chavous, 1998). The items (e.g., 'In general, being Black is an important part of my selfimage') assess the degree of overlap between self and racial ingroup. All items were answered on 7 -point Likert-type scales $(1=$ strongly disagree to $7=$ strongly agree), such that higher scores indicate greater ingroup identity.

Perceived ingroup-directed prejudice was measured with the following: the seven-item ingroup-directed stigmatization subscale of the Johnson-Lecci Scale (JLS; Johnson \& Lecci, 2003); the six-item public regard subscale of the MIBI (Sellers et al., 1998); the 12 likelihood items of the Race-Based Rejection Sensitivity Questionnaire (RBRSQ; Mendoza-Denton, Downey, Purdie, Davis, \& Pietrzak, 2002); and two single items designed by Branscombe et al. (1999) to assess past experience with racial discrimination. The JLS subscale includes items such as 'I believe that most Whites think that they are superior to Blacks' and the MIBI public regard subscale includes items such as 'Blacks are not respected by the broader society'. Both subscales assess the extent to which participants believe that Whites or society at large hold their ingroup in negative esteem. The RBRSQ and perceived discrimination items assess the degree to which participants have been or expect to be mistreated due to their race. The RBRSQ provides participants with scenarios such as: 'Imagine that you are in a pharmacy, trying to pick out a few items. While you're looking at the different brands, you notice one of the store clerks glancing your way'. Participants are then asked to indicate the likelihood with which they would be treated or viewed negatively because of

Table 1. Sequence of IAT Trial Blocks

\begin{tabular}{lllll}
\hline Block & Number of trials & Practice or test & Left category & Right category \\
\hline 1 & 20 & Practice & Black & White \\
2 & 20 & Practice & Pleasant & Unpleasant \\
3 & 20 & Practice & Black or pleasant & White or unpleasant \\
4 & 40 & Test & Black or pleasant & White or unpleasant \\
5 & 20 & Practice & White & Black \\
6 & 20 & Practice & White or pleasant & Black or unpleasant \\
7 & 40 & Test & White or pleasant & Black or unpleasant \\
\hline
\end{tabular}

Note: Whether Black or White was paired with pleasant first was counterbalanced. Whether Black appeared on the left versus right first was counterbalanced. 
their race $(1=$ very unlikely to $6=$ very likely $)$. The perceived discrimination items adopted from Branscombe et al. (1999) assessed participants' perception of their personal victimization due to their race (e.g., 'I consider myself a person who has been deprived of the opportunities that are available to others because of my race'). Participants responded to all items except those from the RBRSQ on 7-point Likert-type scales $(1=$ strongly disagree to $7=$ strongly agree $)$.

To assess psychological well-being, the following scales were used: Rosenberg's (1965) 10-item selfesteem scale, the 5-item Satisfaction with Life scale (Diener, Emmons, Larsen, \& Griffin, 1985), and the 6-item Hope scale (Snyder et al., 1996). Participants responded to the self-esteem (e.g., 'I feel that I have a number of good qualities') and life satisfaction items (e.g., 'The conditions of my life are excellent') on 7-point Likerttype scales $(1=$ strongly disagree to $7=$ strongly agree) and to the hope scale (e.g., 'I can think of many ways to reach my current goals') on an 8-point Likert-type scale $(1=$ definitely false to 8 = definitely true).

The 20-item Beck Depression Inventory ${ }^{3}$ (BDI; Beck, Ward, Mendelson, Mock, \& Erbaugh, 1961) was used to assess psychological distress. On the BDI, participants selected one of four progressively depressive response options for each item (e.g., 1 = I do not feel sad to $4=\mathrm{I}$ am so sad or unhappy that I can't stand it).

\section{Results}

\section{Missing data treatment}

Data from one foreign-born participant who had difficulty understanding English were eliminated. In addition, data from 8 participants who were missing IAT data due to computer error and from 7 participants who failed to complete all of the measures were eliminated, resulting in usable data for 300 participants. Although over $97 \%$ of the remaining sample had complete data and no individual was missing data for more than two measured variables, missing data can be problematic for latent variable models. Thus, the expectation maximization method of imputation (Dempster, Laird, \& Rubin, 1977) was conducted prior to analyses in order to preserve all 300 cases.

\section{Preliminary analyses}

Table 2 provides descriptive statistics, internal consistency reliabilities (where applicable), and correlations among all measured variables. For scales obtained from the extant literature, responses (reverse-scoring when appropriate) were averaged to create indexes such that higher numbers indicate greater levels of each variable. The three Black cultural immersion items created specifically for the present research were left as single-item indicators. Reliabilities for multi-item indexes were acceptable, and correlations among variables presumed to represent the same latent construct were at least moderate in size.

Before proceeding with latent variable analyses, we tested for effects due to task order, participant sex, and experimenter race. Whether participants completed the questionnaires versus the IAT first made no difference in any of the measured variables; thus, task order will not be further discussed. There was a marginally significant effect of participant sex on percentage of close childhood friends (see Table 2), but because females greatly outnumbered males in the present sample, gender differences were not explored further. Finally, experimenter race (i.e., White vs. non-White; there were too few instances of Black experimenters to differentiate nonWhite experimenters) bore little relationship to most of the variables (see Table 2) and is not discussed further.

\section{Overview of latent variable analyses}

We first used confirmatory factor analysis (CFA) to establish the validity of our measurement model and then tested the hypothesized structure of the relationships among the variables. All CFA and Structural Equation Modeling analyses were conducted on centered variables using the maximum likelihood method of estimation with robust methods to correct for non-normality (Curran, West, \& Finch, 1997). ${ }^{4}$ To assess model fit, we examined several indices: the Satorra-Bentler scaled chi-square (S-B $\chi^{2}$; Satorra \& Bentler, 1994), which provides a better 


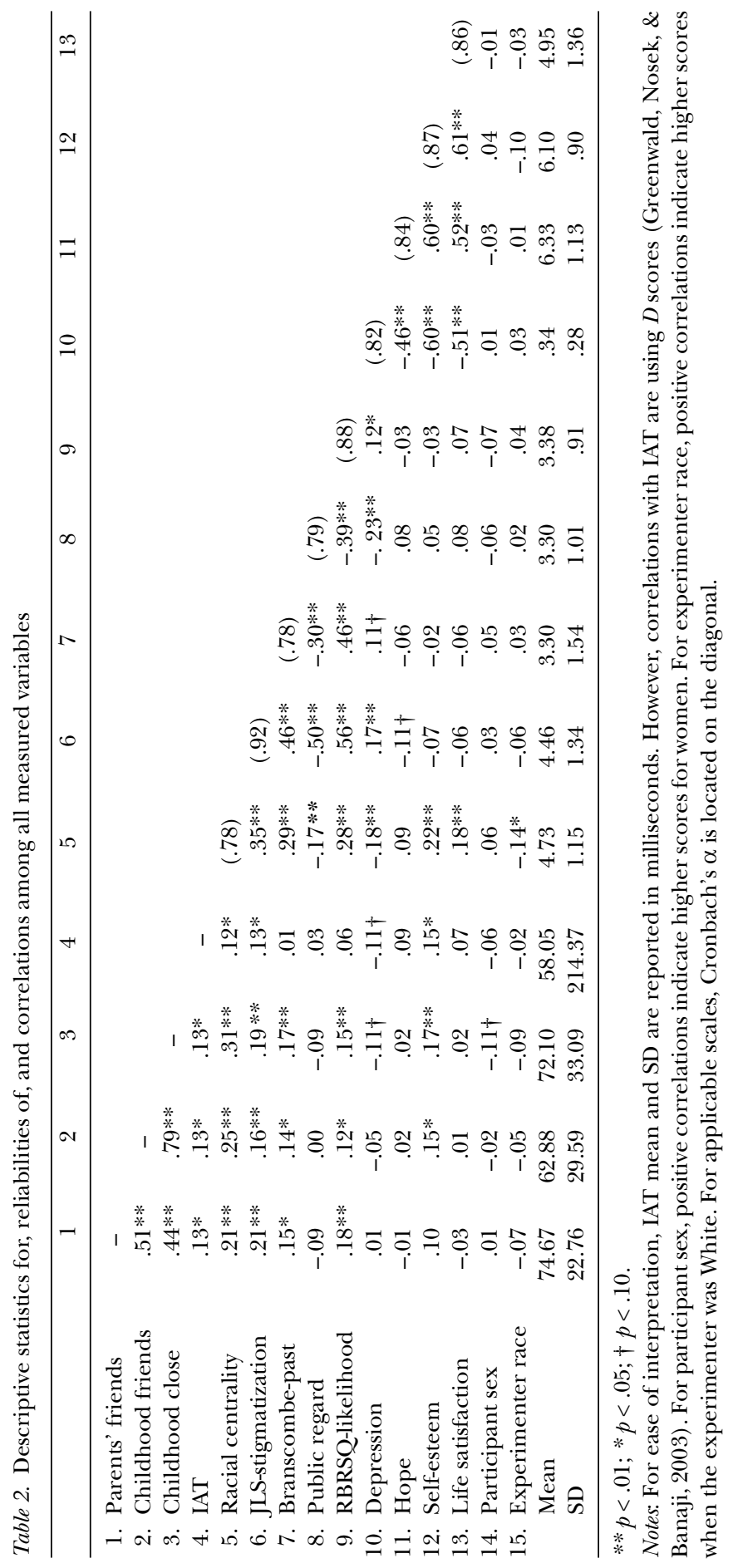


approximation of chi-square under conditions of multivariate non-normality ( $\mathrm{Hu}$, Bentler, \& Kano, 1992); the Comparative Fit Index (CFI), which ranges from 0 to 1 , with values .90 or greater indicating acceptable fit (Bentler, 1990); and the root mean square error of approximation (RMSEA), which is considered indicative of adequate fit when values fall below .08 (Browne \& Cudeck, 1993). RMSEA is typically accompanied by $90 \%$ confidence intervals (CI). Ideally the entire interval, not just the RMSEA value itself, falls below .08 in order to achieve close model fit. In addition, we compared the Akaike Information Criterion (AIC) across models. Unlike the other fit indices, the AIC has little meaning by itself, but it allows one to compare models (regardless of whether they are nested) that are tested with the same data set. The AIC not only assesses goodness of fit, but also penalizes less parsimonious models, such that models with smaller AIC values are preferable (Akaike, 1987).

\section{CFA}

No fewer than three indicators represented each latent variable (Marsh, Hau, Balla, \& Grayson, 1998). Consequently, it was necessary to create random parcels for certain variables, such as the IAT, which typically yields one score per participant. Individual trial response latencies from the IAT were thus divided into four parcels in order to create a latent IAT construct (cf. Cunningham, Nezlek, \& Banaji, 2004). Data within each parcel were treated in accordance with the improved IAT algorithm (Greenwald et al., 2003), which incorporates data from both practice and test blocks, thereby minimizing unsystematic variance due to individual differences in response latencies. Trials with unusually long latencies $(>10,000 \mathrm{~ms})$ were eliminated, as were data from participants who responded unusually fast $(<300 \mathrm{~ms})$ on more than $10 \%$ of the trials. Means were then computed for correct responses within each of the four critical blocks of trials, and two pooled standard deviations were computed based on practice and test blocks respectively. A correction was then applied for trials in which errors were made; specifically, $600 \mathrm{~ms}$ were added to each block mean, and this sum replaced error latencies in their respective blocks. Block means were then recomputed, and a $D$ score was calculated for each participant by subtracting congruent (i.e., Black + pleasant/White + unpleasant) from incongruent (i.e., Black + unpleasant/White + pleasant) block means for both practice and test blocks, dividing each difference by its appropriate standard deviation (practice vs. test), and then averaging these two quotients. Hence, there were four $D$ scores per participant, with positive scores indicating more favorable implicit ingroup attitudes. A similar parceling procedure was employed for racial centrality and the BDI. That is, individual items comprising each scale were randomly divided into four parcels, and items within each parcel were averaged to create mini-indexes.

Indicators were allowed to load on only one latent variable, and all latent variables were allowed to correlate with each other. The measurement model provided a good fit for the data $\left(\mathrm{S}-\mathrm{B} \chi^{2}(194)=277.75, p<.001, \mathrm{CFI}=.96\right.$, RMSEA $=.038(90 \%$ CI: $.027-.048)$. Table 3 provides construct loadings and correlations among latent variables.

The CFA suggested that the measured variables captured the latent variable constructs in hypothesized ways. In addition, correlations among the latent constructs were statistically significant and in the expected directions. Thus, the next step was to examine the structural relationships among the constructs.

\section{Structural relationships}

Below, we report results concerning the three structural models (i.e., identity as antecedent, identity as consequence, and identity as moderator of perceived prejudice) suggested in prior research. Before doing so, we wish to emphasize certain common and critical findings that emerged across analyses, regardless of the particular model being tested. First, we consistently found that the racial variables together accounted for a sizable proportion of the variance in African Americans' psychological health (between $11.9 \%$ and $21.6 \%$, see Table 4 ). 
Table 3. Confirmatory factor analysis

\begin{tabular}{|c|c|c|c|c|c|c|}
\hline \multirow[b]{2}{*}{ Scale } & \multicolumn{6}{|c|}{ Construct loadings } \\
\hline & $\begin{array}{c}\text { Black } \\
\text { cultural } \\
\text { immersion }\end{array}$ & $\begin{array}{l}\text { Implicit } \\
\text { racial } \\
\text { attitudes }\end{array}$ & $\begin{array}{l}\text { Ingroup } \\
\text { identity }\end{array}$ & $\begin{array}{l}\text { Perceived } \\
\text { ingroup- } \\
\text { directed } \\
\text { prejudice }\end{array}$ & $\begin{array}{l}\text { Psychological } \\
\text { well-being }\end{array}$ & $\begin{array}{c}\text { Psychological } \\
\text { distress }\end{array}$ \\
\hline Parents' friends & .55 & & & & & \\
\hline Childhood friends & .92 & & & & & \\
\hline Childhood close & .86 & & & & & \\
\hline IAT parcel 1 & & .67 & & & & \\
\hline IAT parcel 2 & & .77 & & & & \\
\hline IAT parcel 3 & & .73 & & & & \\
\hline IAT parcel 4 & & .75 & & & & \\
\hline Centrality parcel 1 & & & .83 & & & \\
\hline Centrality parcel 2 & & & .77 & & & \\
\hline Centrality parcel 3 & & & .65 & & & \\
\hline Centrality parcel 4 & & & .58 & & & \\
\hline JL S-stigmatization & & & & .81 & & \\
\hline Branscombe-past & & & & .59 & & \\
\hline Public regard & & & & -.58 & & \\
\hline RBRSQ-likelihood & & & & .70 & & \\
\hline Hope & & & & & .69 & \\
\hline Self-esteem & & & & & .86 & \\
\hline Life satisfaction & & & & & .72 & \\
\hline BDI parcel 1 & & & & & & .78 \\
\hline BDI parcel 2 & & & & & & .69 \\
\hline BDI parcel 3 & & & & & & .84 \\
\hline \multirow[t]{2}{*}{ BDI parcel 4} & & & & & & .74 \\
\hline & \multicolumn{6}{|c|}{ Latent variable correlations } \\
\hline Black cultural immersio & on & & & & & \\
\hline Implicit racial attitudes & .16 & - & & & & \\
\hline Ingroup identity & .35 & .15 & - & & & \\
\hline \multicolumn{7}{|l|}{ Perceived ingroup- } \\
\hline directed prejudice & .22 & .10 & .43 & - & & \\
\hline Psychological well-being & .13 & .13 & .27 & -.09 & - & \\
\hline Psychological distress & -.08 & -.12 & -.23 & .25 & -.77 & - \\
\hline
\end{tabular}

Table 4. Comparison of structural models

\begin{tabular}{|c|c|c|c|c|c|c|c|}
\hline & $\mathrm{S}-\mathrm{B} \chi^{2}$ & $d f$ & AIC & CFI & RMSEA $(90 \%$ CI) & $\begin{array}{c}R^{2} \text { in well } \\
\text { being }\end{array}$ & $\begin{array}{c}R^{2} \text { in } \\
\text { distress }\end{array}$ \\
\hline Identity as antecedent & 282.5865 & 199 & -115.413 & .960 & $.037(.027-.047)$ & .136 & .216 \\
\hline $\begin{array}{l}\text { Identity as antecedent setting } \\
\text { all structural paths involving } \\
\text { implicit racial attitudes to } 0\end{array}$ & 290.9809 & 202 & -113.019 & .957 & $.038(.028-.048)$ & .128 & .207 \\
\hline Identity as consequence & 296.6058 & 199 & -101.394 & .953 & $.041(.030-.050)$ & .125 & .208 \\
\hline $\begin{array}{l}\text { Identity as consequence setting } \\
\text { all structural paths involving } \\
\text { implicit racial attitudes to } 0\end{array}$ & 304.9355 & 202 & -99.064 & .951 & $.041(.031-.050)$ & .119 & .200 \\
\hline
\end{tabular}


Race-related attitudes and perceptions were especially important to psychological distress. This is consistent with models that suggest that racism is a major stressor for African Americans (Clark et al., 1999). While African Americans as a group may not experience more depression than Whites (Zhang \& Snowden, 1999), racial factors clearly play a role in what they do experience.

Second, early positive contact with other ingroup members was significantly associated with more positive implicit ingroup attitudes, and it significantly predicted stronger ingroup identity (see Figures 4 and 5). These findings are consistent with both theory regarding the origins of implicit attitudes (e.g., Rudman, 2004) and with empirical findings regarding sociocultural immersion (Greenwald et al., 1998).

Third, implicit racial attitudes predicted both well-being and distress, such that implicitly favoring their ingroup relative to Whites was associated with more positive psychological functioning and less depression among African Americans (see Figures 4 and 5). To our knowledge, this is the first empirical demonstration of the personal significance of such associations for the global mental health of a stigmatized group.
Identity as antecedent One of the structural relationships we tested was the identity as antecedent model depicted in Figure 1. As shown in the first row of Table 4, the model provided a good fit for the data and accounted for a substantial portion of the variance in both psychological well-being $(13.6 \%)$ and psychological distress $(21.6 \%)$. The path coefficients are presented in Figure 4. Consistent with previous research, strongly identifying with one's ingroup was directly associated with better psychological health (e.g., Branscombe et al., 1999; Postmes \& Branscombe, 2002), butalso indirectly associated with poorer mental health outcomes via perceived prejudice (e.g., Eccleston \& Major, 2006; Sellers \& Shelton, 2003). Thus, although ingroup identity offers psychological benefits, it also appears to function as a 'lens' that magnifies perceptions of ingroup-directed prejudice (Eccleston \& Major, 2006).

Given our emphasis on implicit racial attitudes and the fact that this latent construct yielded relatively small, though significant, correlations with other latent constructs in both the CFA and the identity as antecedent SEM, we also tested a model that constrained the structural paths involving implicit racial attitudes to 0 . That is,

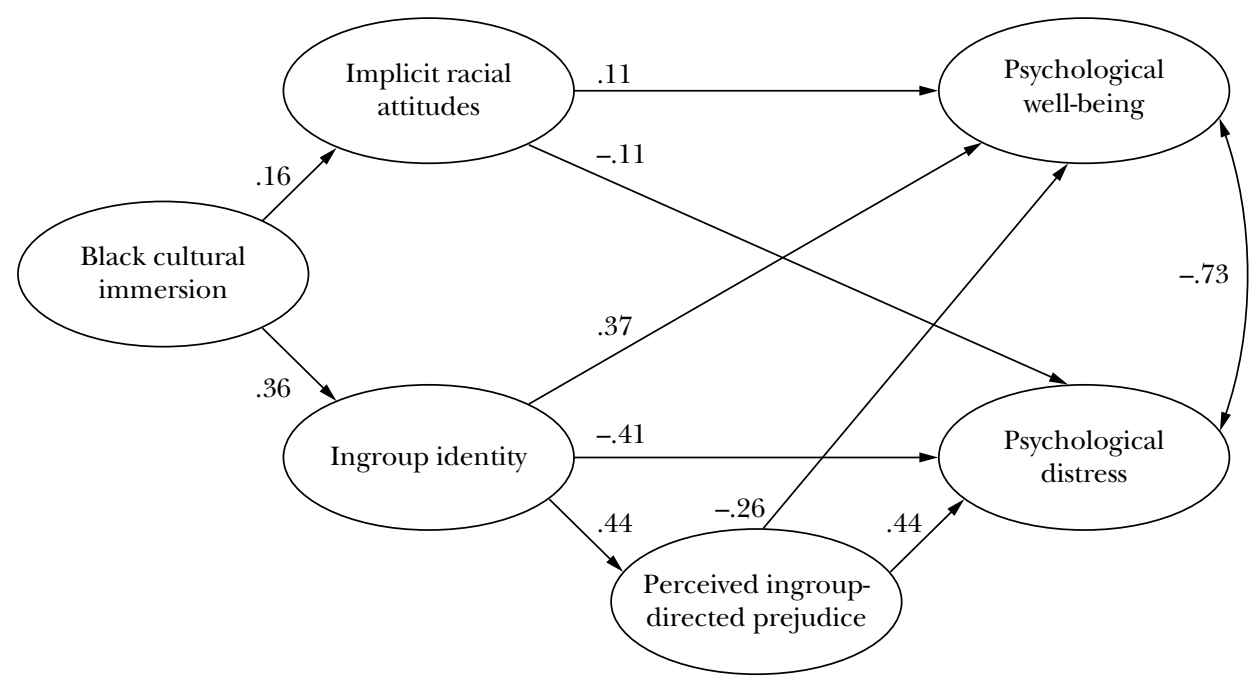

Figure 4. Standardized solution for test of identity as antecedent model. All paths are significant at $p<.05$. The path between psychological well-being and distress is actually between the two variables' disturbance terms. 


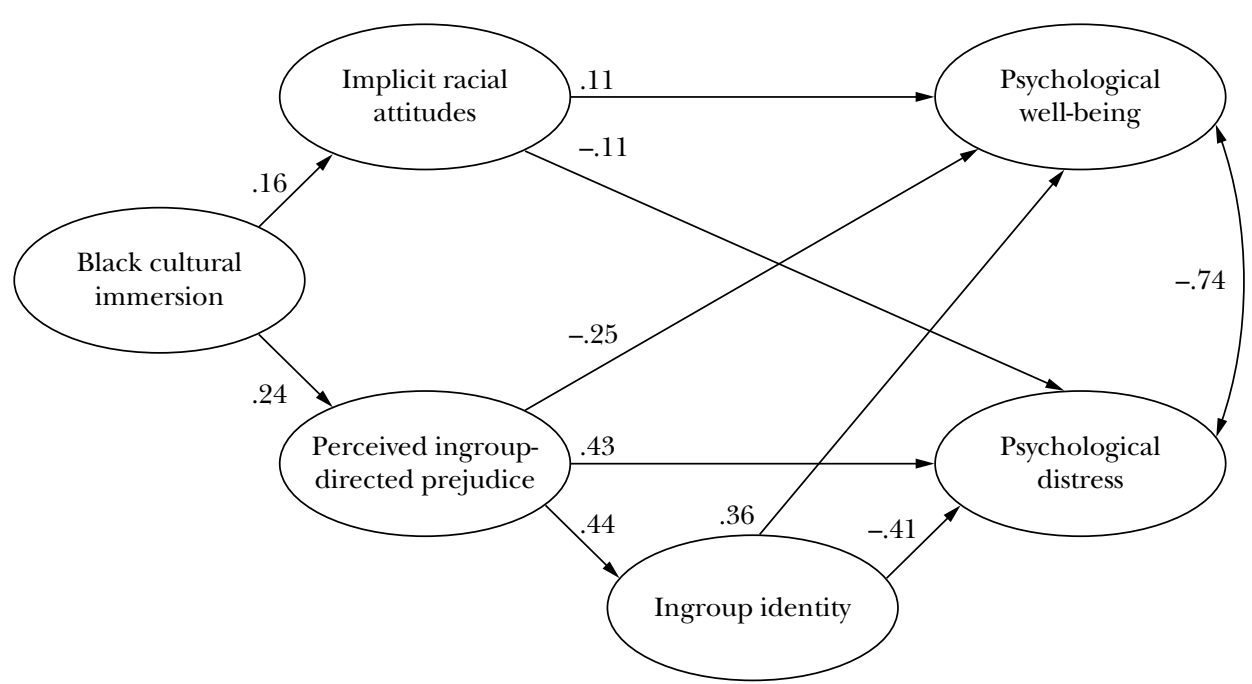

Figure 5. Standardized solution for test of identity as consequence model. All paths are significant at $p<.05$. The path between psychological well-being and distress is actually between the two variables' disturbance terms.

Black cultural immersion was assumed not to predict implicit racial attitudes, and implicit racial attitudes were assumed not to predict the psychological health constructs. As shown in row 2 of Table 4 , this resulted in worse fit than the previous model, though clearly the changes in each fit index were small. However, because these models were nested, we were able to examine whether the decline in model fit was statistically significant. Indeed, it was, $\left(\Delta \chi^{2}(3)=8.39, p<.04\right)$. Thus, whereas it is obvious that implicit racial attitudes exhibited small effects in relation to other variables, their role is nonetheless significant.

Identity as consequence Next we tested the identity as consequence model. As shown in row 3 of Table 4, this model also provided an adequate, though worse fit for the data than the identity as antecedent model, provided a less parsimonious account of the data, and it accounted for slightly less variance in both outcome variables. As shown in Figure 5, the paths among the variables were significant and in the hypothesized directions. That is, perceived prejudice exhibited both directly detrimental and indirectly (via ingroup identity) beneficial relationships with psychological health. Thus, identity appeared to serve as a 'resource' for stigmatized persons (Eccleston \& Major, 2006), resulting from their experiences with and perceptions of prejudice. Such findings are consistent with the theorizing of Branscombe and her colleagues (e.g., Branscombe et al., 1999; Postmes \& Branscombe, 2002), as is the fact that Black cultural immersion predicted greater perceptions of ingroup-directed prejudice. Specifically, Postmes and Branscombe found that being in contact with other ingroup members was associated with greater feelings of negativity from the outgroup, and in turn, stronger ingroup identity.

We next retested the identity as consequence model constraining the implicit racial attitudes paths to 0 to determine whether the construct made a significant contribution to the identity as consequence model. As shown in row 4 of Table 4 , the resulting fit was adequate, but provided the worst fit of all four models tested according to the AIC. In addition, compared with the identity as consequence model that allowed the paths involving implicit racial attitudes to vary freely, this model provided significantly worse fit, $\left(\Delta \chi^{2}(3)=8.33, p<.04\right)$, again underscoring the 
importance of implicit attitudes to the bigger picture of race and psychological health for African Americans.

Identity as moderator Tests of moderation in SEM require the calculation of interaction terms not only for the variables of interest, but also for all of their error terms. Given the already large number of indicators for the predictor variables relative to sample size in the present research, we were concerned that conducting tests of moderation with SEM would compromise power. Thus, in separate multiple regression analyses, we regressed psychological well-being and psychological distress on implicit racial attitudes, perceived ingroup-directed prejudice, ingroup identity, and all possible interactions among these predictors.

To do so, we first standardized participants' scores on variables that were indicated by multiple measures (i.e., perceived ingroup-directed prejudice, psychological well-being, and Black cultural immersion) and averaged them to create composite indexes. For variables that previously were parceled for purposes of creating multiple indicators for the latent constructs (i.e., implicit racial attitudes, ingroup identity, and psychological distress), we used participants' original total scores on the IAT, racial centrality subscale, and BDI. We then entered the Black cultural immersion composite in the first step of each regression to replicate its role as the exogenous variable in the comprehensive SEM. The main effects of implicit racial attitudes, ingroup identity, and perceived prejudice were entered in the second step, two-way interactions in the third step, and the three-way interaction in the fourth step.

The findings mirrored those obtained via SEM. Specifically, Black cultural immersion did not directly predict either psychological well-being or psychological distress, but implicit racial attitudes, ingroup identity, and perceived prejudice did. However, for psychological wellbeing, the main effect of perceived prejudice was qualified by a marginally significant twoway interaction with ingroup identity $(\beta=.11$, $t(292)=1.93, p<.06)$. The interaction is depicted in Figure 6, with values retrieved at 1 $\mathrm{SD}$ above and below the means of the predictor variables. For participants who were low in ingroup identity, greater perceptions of prejudice

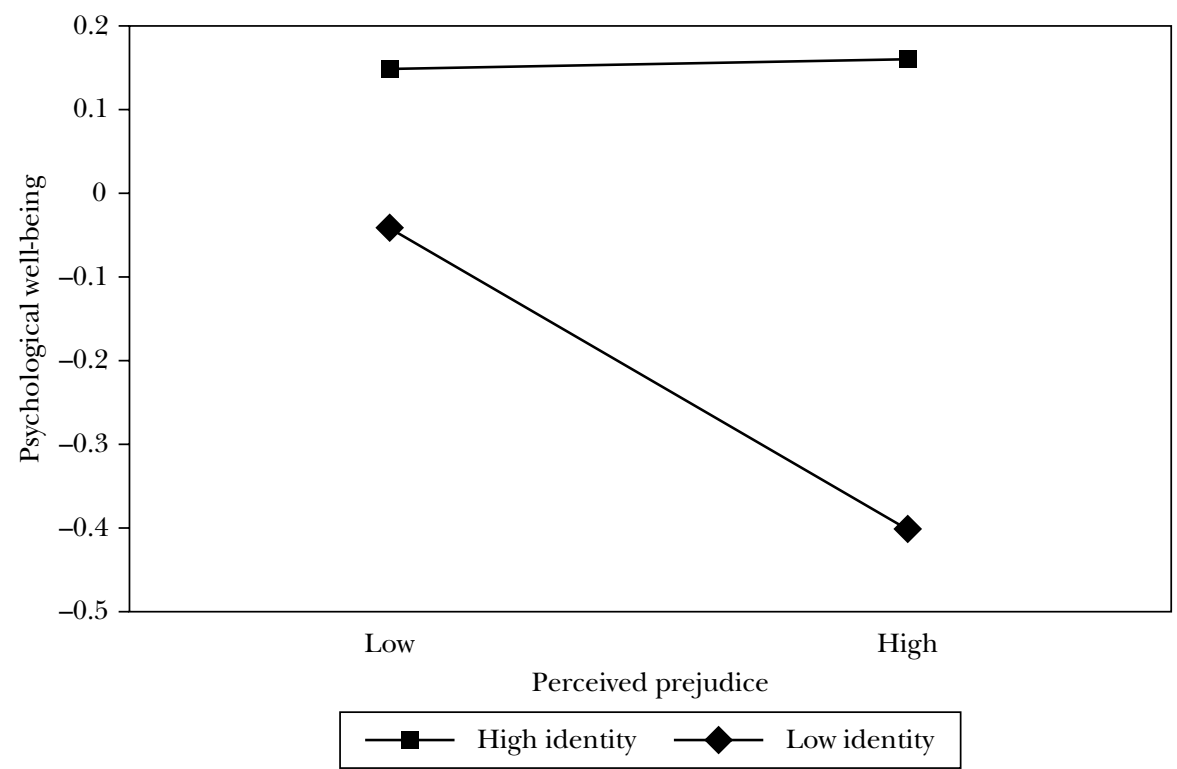

Figure 6. Psychological well-being as a function of ingroup identity and perceived ingroup-directed prejudice. 
were associated with poorer psychological well-being $(\beta=-.21, t(296)=2.60, p=.01)$. However, participants who highly identified with their ingroup were impervious to the negative effects of perceived prejudice $(\beta=.01, t<1, n s)$ Thus, ingroup identity buffered well-being from perceptions of ingroup-directed prejudice. Taken together, the main effects and two-way interactions accounted for approximately $7.1 \%$ of the variance in psychological well-being and $6.7 \%$ of the variance in psychological distress.

\section{Discussion}

The present findings suggest that the psychological welfare of African Americans depends in part on a complex network of racial factors. Previous studies of stigma and mental health provided a foundation by underscoring the importance of perceived prejudice and ingroup identity, but to date studies have lacked the breadth of variables included in the present research. Furthermore, previous studies have focused on either positive or negative aspects of psychological functioning, making it difficult to determine whether stigma differentially affects psychological well-being versus distress. Through our more comprehensive approach, we were able to account for a greater proportion of variance and better determine the significance of racial factors for African Americans' psychological health. Indeed, accounting for approximately $12 \%$ of the variance in psychological well-being and approximately $18 \%$ of the variance in psychological distress (i.e., averaging across the models tested) is quite remarkable. Prior research into the population at large has been able to account for nearly this much variance in wellbeing only when using many crucial predictors simultaneously, such as wealth, religion, and fulfilling relationships (Campbell, Converse, \& Rodgers, 1976). The present data are among the first to demonstrate that there are stronger implications of stigma for distress than for more positive aspects of psychological health.

The present research also highlights the independent contribution of implicit racial attitudes to mental health outcomes. Despite their growing popularity in recent years, some important questions remain about implicit measures, especially the IAT (Fazio \& Olson, 2003). These include concerns about predictive validity and about what such biases actually reflect. In terms of predictive validity, the racial IAT has been shown to predict, for example, Whites' avoidance behaviors (e.g., less speaking time, more speech hesitations) toward Black targets (McConnell \& Liebold, 2001) as well as African Americans' racial preferences for a partner with whom they believed they would complete an intellectually challenging task (Ashburn-Nardo et al., 2003). The present study adds to these findings by demonstrating the IAT's ability to predict constructs of perhaps even greater personal importance: psychological well-being and psychological distress. Finding that the IAT predicts both health outcomes in a theoretically sensible way strengthens its predictive value and provides evidence to support recent arguments that the measure reflects participants' own evaluative associations and not merely selfirrelevant or extrapersonal knowledge of societal evaluations of Blacks versus Whites (Nosek \& Hansen, 2004).

Indeed, due to the emergence of the extrapersonal versus personal IAT debate following our primary data collection efforts, we administered the original IAT as well as a modified 'personalized' IAT designed by Olson and Fazio (2004) to minimize the influence of the target groups' portrayal in society (i.e., with Whites portrayed more positively than Blacks) to a separate sample of 60 African American participants. In the modified IAT, the category label pleasant is replaced by I like and unpleasant is replaced by I don't like to make personal evaluations of target exemplars more salient. Also, error feedback is eliminated to reduce the likelihood that participants interpret the task as involving normatively appropriate and inappropriate responses. If the original IAT is susceptible to extrapersonal influences, as Olson and Fazio suggested, then one would expect participants to exhibit less favorable ingroup associations on the original versus modified IAT. This was not the case. Rather, means and standard deviations were comparable across IAT versions, and a paired-samples $t$ test indicated no 
reliable difference $(p=.84)$. We also found that the original and modified IATs showed the same magnitude of relation with explicitly reported ingroup attitudes $(r \mathrm{~s}=.33$ and .31 , respectively, $p \mathrm{~s}<.02)$, and neither was significantly related to participants' perceptions of how society evaluates African Americans $(r \mathrm{~s}=.10$ and .16 , respectively, $p \mathrm{~s}>.23$ ). These data do not suggest that the modified IAT is more appropriate for use with African Americans than the original IAT. Likewise, Nosek and Hansen (2004) made multiple comparisons of the original and modified IATs across a variety of evaluative dimensions and found little evidence to suggest that the modified IAT offers advantages over the original version.

The present IAT findings also speak to an issue that has gained much attention in the last few years; that is, what are the sources of implicit attitudes? Consistent with previous research underscoring the importance of sociocultural experiences, particularly from childhood, in shaping implicit associations (Greenwald et al., 1998; Rudman, 2004; Rudman \& Goodwin, 2004), African Americans' implicit racial attitudes appear to stem from an immersion in Black culture from an early age.

Unfortunately, we were unable to compare directly the contributions of African Americans' implicit with their self-reported ingroup attitudes. As indicated in Note 1, we did include a measure of explicit private ingroup regard, but participants responded near ceiling and with little variability, thus rendering the explicit attitude measure of little use for our purposes. This further underscores the utility of implicit measures. The social cognitive literature has made it increasingly clear that individuals are often unable to access and report self-relevant attitudes. This might especially be the case for stigmatized groups such as African Americans, considering the efforts made historically (e.g., Black power, Black is beautiful) to improve their self-views. Indeed, the present findings add to a growing literature demonstrating the utility of implicit measures with African American samples (Ashburn-Nardo et al., 2003; Livingston, 2002; Nosek et al., 2002; Spicer, 1999) or other low-status groups (Jost, Pelham, \& Carvallo, 2002; Rudman, Feinberg, \& Fairchild, 2002).

The present research lends greater generalizability and converging evidence to other studies that have examined the psychological health of stigmatized individuals. Although previous research identified important racial factors that predict aspects of psychological health, there were methodological differences that made it difficult to see the bigger picture. For example, Branscombe and colleagues (Branscombe et al., 1999; Postmes \& Branscombe, 2002) defined well-being as positive attitudes toward both self and ingroup; in contrast, Sellers and Shelton (2003) focused on variables of distress, such as anxiety and depression. By expanding our operational definitions of psychological health, identity, and perceived prejudice, a clearer interpretation of race and African Americans' mental welfare emerged.

But what is clear is that nothing is straightforward about these variables and their implications for psychological health. We considered three models, all based on findings in the extant literature. In one model, ingroup identity served as an antecedent to perceived prejudice and was indirectly associated negatively with psychological health. In another, ingroup identity served as a consequence of perceived prejudice and in turn, correlated positively with psychological health. Both models provided adequate fit for the data and accounted for comparable portions of the variance in well-being and distress. We also considered a model in which ingroup identity was a moderator of perceived prejudice, and indeed stronger identity functioned as a buffer to protect stigmatized individuals' psychological well-being from perceived prejudice. In light of these and previous findings (e.g., Eccleston \& Major, 2006), it is perhaps safest to conclude that ingroup identity and perceived prejudice operate in a cyclical manner, with stronger identity increasing one's awareness of ingroupdirected prejudice, and increased perceptions of prejudice strengthening ingroup ties and ultimately protecting individuals from further psychological harm. 


\section{Limitations and future directions}

Despite the advantages of SEM (e.g., controlling for measurement error), it is important to remember that the ability to make causal inferences in any study is limited by its design. SEM has some unfortunate misnomers (e.g., causal modeling) but because the present data are cross-sectional and correlational in nature, one cannot say with certainty that any of the predictors is a cause of psychological health. All of the directional arrows in the models we tested are based on our interpretation of the extant literature. For example, in light of recent theorizing regarding the sources of implicit attitudes (e.g., Rudman, 2004), we assumed that Black cultural immersion had temporal precedence over implicit racial attitudes. Given the difficulty in experimentally manipulating such variables, longitudinal data would have been ideal.

One might also argue that the present study is limited by the relatively modest contribution of implicit racial attitudes to psychological health. While the effect size is small by convention, its unique relationship with psychological health outcomes suggests the need to continue to examine the implicit racial attitudes of stigmatized persons and their implications. In addition, using an implicit measure (the IAT) to predict self-reported psychological welfare might have contributed to the modest effect sizes given the unshared method variance. Future research might see greater correspondence between implicit measures and, for example, physiological indicators of mental or physical health (e.g., blood pressure reactivity) over which people have less conscious control. Finally, replicating findings in a more gender-balanced, non-college sample would bolster the external validity of the present research. Likewise, although the variables assessed herein likely operate similarly with other stigmatized groups, future research should compare the present results with those of other populations. This is especially the case for implicit attitudes, given that the lower in status the ingroup, the more negative their implicit ingroup attitudes tend to be (Rudman et al., 2002). Perhaps such attitudes would have even greater psychological implications for members of groups for which there are weaker anti-prejudice norms than there are for African Americans.

\section{Conclusion}

In conclusion, our results suggest that providing good models of and encouraging close relationships with ingroup members from an early age are good pieces of advice for promoting positive ingroup identity and implicit attitudes and, in turn, psychological welfare in stigmatized persons. Although this strategy might also increase attention to ingroupdirected prejudice, the negative effects appear to be outweighed by the benefits. Like previous studies that demonstrated the malleability of implicit associations (Dasgupta \& Greenwald, 2001; Rudman et al., 2001), the present findings provide reason for optimism that both implicit attitudes and ingroup identity may be influenced in positive ways, which may ultimately lead to a happier, more satisfying life.

\section{Notes}

1. Participants completed additional measures to assess explicit ingroup attitudes and egalitarian ideology, but these variables were dropped after initial analyses because they were associated with various problems. For example, the confirmatory factor analysis (CFA) was especially affected by our attempt to include explicit ingroup attitudes as a latent variable. First, its restricted range $(M=6.65, S D=0.52)$ significantly worsened multivariate non-normality. In addition, the CFA results suggested that the greatest model misspecification involved the indicators of the explicit ingroup attitudes construct, which cross-loaded on both psychological well-being and perceived ingroup-directed prejudice. Similar restrictions in range were observed for the indicators of egalitarian ideology. These variables were thus of little explanatory value in the models and were consequently dropped from the presented analyses.

2. Participants completed several other Black cultural immersion items, including some adapted from items used by Postmes and 
Branscombe (2002) to assess long-term racial segregation. These items concerned intergroup contact that was neither necessarily close nor of personal choice (e.g., the percentage of Blacks in one's elementary school). Exploratory factor analyses indicated that these items did not form a unitary construct nor did they perform well in other (e.g., reliability) analyses. The specific items are available upon request.

3. The BDI contains 21 items, but the University of Kentucky Institutional Review Board disallowed use of the item concerning suicide.

4. Analyses assuming multivariate normality yielded very similar results; however, given that Mardia's coefficient (Mardia, 1970) for our data suggested multivariate kurtosis, robust statistics are more appropriate estimates.

\section{Acknowledgements}

Portions of this research were based on an undergraduate honors thesis submitted by Amber Bain to the University of Kentucky and were presented at the Annual Convention of the Society for Personality and Social Psychology, New Orleans, LA, January 2005. The research was supported in part by National Institute of Mental Health Grant MH56536 and a University of Kentucky Research Committee Grant to Margo Monteith. We would like to thank Elizabeth Cloyd, Michelle Corman, Kate Emswiller, Abi French, Marc Gentzler, Tammy Goni, Robert Hargis, Lindsay Sharp, Jamarcus Smith, and Yvonne Wallace for assistance with data collection.

\section{References}

Aberson, C. L., Shoemaker, C., \& Tomolillo, C. (2004). Implicit bias and contact: The role of interethnic friendships. Journal of Social Psychology, 144, 335-347.

Akaike, H. (1987). Factor analysis and AIC. Psychometrika, 52, 317-332.

Allport, G. W. (1954/1979). The nature of prejudice. Cambridge, MA: Perseus Books.

Ashburn-Nardo, L. (2004). (Unraveling) the ties that bind: The impact of stigma on the implicit self-concept. Unpublished manuscript, Indiana UniversityPurdue University Indianapolis.

Ashburn-Nardo, L., Knowles, M. L., \& Monteith, M. J. (2003). Black Americans' implicit racial associations and their implications for intergroup judgment. Social Cognition, 21, 61-87.
Ashburn-Nardo, L., Voils, C. I., \& Monteith, M. J. (2001). Implicit associations as the seeds of intergroup bias: How easily do they take root? Journal of Personality and Social Psychology, 81, 789-799.

Beck, A. T., Ward, C. H., Mendelson, M., Mock, J., \& Erbaugh, J. (1961). An inventory for measuring depression. Archives of General Psychiatry, 4, 561-571.

Bentler, P. M. (1990). Comparative fit indexes in structural models. Psychological Bulletin, 107, 238-246.

Blair, I. V. (2001). Implicit stereotypes and prejudice. In G. B. Moskowitz (Ed.), Cognitive social psychology: The Princeton symposium on the legacy and future of social cognition (pp. 359-374). Mahwah, NJ: Erlbaum.

Branscombe, N. R., Schmitt, M. T., \& Harvey, R. D. (1999). Perceiving pervasive discrimination among African Americans: Implications for group identification and well-being. Journal of Personality and Social Psychology, 77, 135-149.

Brauer, M., Wasel, W., \& Niedenthal, P. (2000). Implicit and explicit components of prejudice. Review of General Psychology, 4, 79-101.

Browne, M. W., \& Cudeck, R. (1993). Alternative ways of assessing model fit. In K. A. Bollen \& J. S. Long (Eds.), Testing structural equation models (pp. 136-162). Newbury Park, CA: Sage.

Campbell, A., Converse, P. E., \& Rodgers, W. L. (1976). The quality of American life. New York: Russell Sage Foundation.

Clark, R., Anderson, N. B., Clark, V. R., \& Williams, D. R. (1999). Racism as a stressor for African Americans: A biopsychosocial model. American Psychologist, 54, 805-816.

Crosby, F., Bromley, S., \& Saxe, L. (1980). Recent unobtrusive studies of Black and White discrimination and prejudice: A literature review. Psychological Bulletin, 87, 546-563.

Cross, W. (1978). The Thomas and Cross models of psychological nigrescence: A literature review. Journal of Black Psychology, 4, 13-31.

Cunningham, W. A., Nezlek, J. B., \& Banaji, M. R. (2004). Implicit and explicit ethnocentrism: Revisiting the ideologies of prejudice. Personality and Social Psychology Bulletin, 30, 1332-1346.

Curran, P. J., West, S. G., \& Finch, J. F. (1997). The robustness of test statistics to nonnormality and specification error in confirmatory factor analysis. Psychological Methods, 1, 16-29.

Dasgupta, N., \& Greenwald, A. G. (2001). On the malleability of automatic attitudes: Combating automatic prejudice with images of admired and 
disliked individuals. Journal of Personality and Social Psychology, 81, 800-814.

Dempster, A. P., Laird, N. M., \& Rubin, D. B. (1977). Maximum likelihood from incomplete data via the EM algorithm. Journal of the Royal Statistical Society, Series B, 39, 1-38.

Devine, P. G. (1989). Stereotypes and prejudice: Their automatic and controlled components. Journal of Personality and Social Psychology, 56, 5-18.

Diener, E., Emmons, R. A., Larsen, R. J., \& Griffin, S. (1985). The Satisfaction with Life Scale. Journal of Personality Assessment, 49, 71-75.

Dovidio, J. F., Kawakami, K., \& Beach, K. R. (2001). Implicit and explicit attitudes: Examination of the relationship between measures of intergroup bias. In R. Brown \& S. L. Gaertner (Eds.), Blackwell handbook of social psychology: Intergroup processes (pp. 175-197). Malden, MA: Blackwell.

Eccleston, C. P., \& Major, B. N. (2006). Attributions to discrimination and self-esteem: The role of group identification and appraisals. Group Processes Intergroup Relations, 9, 147-162.

Fazio, R. H., \& Olson, M. A. (2003). Implicit measures in social cognition: Their meaning and use. Annual Review of Psychology, 54, 297-327.

Graham, S. (1992). 'Most of the subjects were White and middle class': Trends in published research on African Americans in selected APA journals, 1970-1989. American Psychologist, 47, 629-639.

Greenwald, A. G., McGhee, D. E., \& Schwartz, J. L. K. (1998). Measuring individual differences in implicit cognition: The Implicit Association Test. Journal of Personality and Social Psychology, 74, 1464-1480.

Greenwald, A. G., Nosek, B. A., \& Banaji, M. R. (2003). Understanding and using the Implicit Association Test: I. An improved scoring algorithm. Journal of Personality and Social Psychology, 85, 197-216.

Hu, L.-T., Bentler, P. M., \& Kano, Y. (1992). Can test statistics in covariance structure analysis be trusted? Psychological Bulletin, 112, 351-362.

Johnson, J. D., \& Lecci, L. (2003). Assessing antiWhite attitudes and predicting perceived racism: The Johnson-Lecci Scale. Personality and Social Psychology Bulletin, 29, 299-312.

Jost, J. T., Pelham, B., \& Carvallo, M. (2002). Non-conscious forms of system justification: Cognitive, affective, and behavioral preferences for higher status groups. Journal of Experimental Social Psychology, 38, 586-602.
Karpinski, A., \& Hilton, J. L. (2001). Attitudes and the Implicit Association Test. Journal of Personality and Social Psychology, 81, 774-788.

Livingston, R. W. (2002). The role of perceived negativity in the moderation of African Americans' implicit and explicit racial attitudes. Journal of Experimental Social Psychology, 38, 405-413.

Major, B., \& O'Brien, L. T. (2005). The social psychology of stigma. Annual Review of Psychology, 56, 393-421.

Major, B., \& Vick, S. B. (2005). The psychological impact of prejudice. In J. F. Dovidio, P. Glick, \& L. A. Rudman (Eds.), On the nature of prejudice: Fifty years after Allport (pp. 139-154). Malden, MA: Blackwell.

Mardia, K. V. (1970). Measures of multivariate skewness and kurtosis with applications. British Journal of Mathematical and Statistical Psychology, 28, 205-214.

Marsh, H. W., Hau, K.-T., Balla, J. R., \& Grayson, D. (1998). Is more ever too much? The number of indicators per factor in confirmatory factor analysis. Multivariate Behavioral Research, 33, 181-220.

McConnell, A. R., \& Liebold, J. M. (2001). Relations among the Implicit Association Test, discriminatory behavior, and explicit measures of racial attitudes. Journal of Experimental Social Psychology, 37, 435-442.

McCoy, S. K., \& Major, B. (2003). Group identification moderates emotional responses to perceived prejudice. Personality and Social Psychology Bulletin, 29, 1005-1017.

Mendoza-Denton, R., Downey, G., Purdie, V. J., Davis, A., \& Pietrzak, J. (2002). Sensitivity to status-based rejection: Implications for African American students' college experience. Journal of Personality and Social Psychology, 83, 896-918.

Nosek, B. A., Banaji, M. R., \& Greenwald, A. G. (2002). Harvesting implicit group attitudes and beliefs from a demonstration website. Group Dynamics, 6, 101-115.

Nosek, B. A., \& Hansen, J. J. (2004). The associations in our heads belong to us: Searching for attitudes and knowledge in implicit evaluation. Unpublished manuscript, University of Virginia.

Olson, M. A., \& Fazio, R. H. (2004). Reducing the influence of extrapersonal associations on the Implicit Association Test: Personalizing the IAT. Journal of Personality and Social Psychology, 86, 653-667. 
Olsson, A., Ebert, J. P., Banaji, M. R., \& Phelps, E. A. (2005). The role of social groups in the persistence of learned fear. Science, 309, 785-787.

Operario, D., \& Fiske, S. T. (2001). Ethnic identity moderates perceptions of prejudice: Judgments of personal versus group discrimination and subtle versus blatant bias. Personality and Social Psychology Bulletin, 27, 550-561.

Pettigrew, T. F., \& Tropp, L. R. (2000). Does intergroup contact reduce prejudice? Recent meta-analytic findings. In S. Oskamp (Ed.), Reducing prejudice and discrimination. 'The Claremont symposium on applied social psychology' (pp. 93-114). Mahwah, NJ: Erlbaum.

Phinney, J. (1989). Stages of ethnic identity development in minority group adolescents. Journal of Early Adolescence, 9, 34-49.

Postmes, T., \& Branscombe, N. R. (2002). Influence of long-term racial environmental composition on subjective well-being in African Americans. Journal of Personality and Social Psychology, 83, 735-751.

Rosenberg, M. (1965). Society and the adolescent selfimage. Princeton, NJ: Princeton University Press.

Rudman, L. A. (2004). Sources of implicit attitudes. Current Directions in Psychological Science, 13, 79-82.

Rudman, L. A., Ashmore, R. D., \& Gary, M. L. (2001). 'Unlearning' automatic biases: The malleability of implicit prejudice and stereotypes. Journal of Personality and Social Psychology, 81, 856-868.

Rudman, L. A., Feinberg, J., \& Fairchild, K. (2002). Minority members' implicit attitudes: Automatic ingroup bias as a function of group status. Social Cognition, 20, 294-320.

Rudman, L. A., \& Goodwin, S. A. (2004). Gender differences in automatic in-group bias: Why do women like women more than men like men? Journal of Personality and Social Psychology, 87, 494-509.

Satorra, A., \& Bentler, P. M. (1994). Corrections to test statistics and standard errors on covariance structure analysis. In A. von Eye \& C. C. Clogg (Eds.), Latent variable analysis (pp. 399-419). Thousand Oaks, CA: Sage.

Sellers, R. M., \& Shelton, J. N. (2003). The role of racial identity in perceived racial discrimination. Journal of Personality and Social Psychology, 84, 1079-1092.

Sellers, R. M., Smith, M. A., Shelton, J. N., Rowley, S. A. J., \& Chavous, T. M. (1998). Multidimensional model of racial identity:
A reconceptualization of African American racial identity. Personality and Social Psychology Review, 2, 18-39.

Shelton, J. N. (2000). A reconceptualization of how we study issues of racial prejudice. Personality and Social Psychology Review, 4, 374-390.

Smith, E. R., \& Henry, S. (1996). An ingroup becomes part of the self: Response time evidence. Personality and Social Psychology Bulletin, 22, 635-642.

Snyder, C. R., Sympson, S. C., Ybasco, F. C., Borders, T. F., Babyak, M. A., \& Higgins, R. L. (1996). Development and validation of the State Hope Scale. Journal of Personality and Social Psychology, 70, 321-335.

Spicer, C. V. (1999). Effects of self-stereotyping and stereotype threat on African Americans' intellectual performance. Unpublished doctoral dissertation, University of Kentucky, Lexington, Kentucky.

Staw, B. M., Sutton, R. I., \& Pelled, L. H. (1994). Employee positive emotion and favorable outcomes in the workplace. Organization Science, 5, 51-71.

Swim, J. K., \& Stangor, C. (1998). Prejudice: The target's perspective. San Diego, CA: Academic Press.

Tajfel, H., \& Turner, J. C. (1986). An integrative theory of intergroup relation. In S. Worchel \& W. G. Austin (Eds.), Psychology of intergroup relations (pp. 7-24). Chicago, Nelson-Hall.

Tropp, L. R., \& Wright, S. C. (2001). Ingroup identification as the inclusion of ingroup in the self. Personality and Social Psychology Bulletin, 27, 585-600.

Veenhoven, R. (1988). The utility of happiness. Social Indicators Research, 20, 333-354.

Zhang, A. Y., \& Snowden, L. R. (1999). Ethnic characteristics of mental disorders in five U.S. communities. Cultural Diversity and Ethnic Minority Psychology, 5, 134-146.

Paper received 25 January 2006; revised version accepted 27 November 2006.

\section{Biographical notes}

LESLIE ASHBURN-NARDo received her Ph.D. from the University of Kentucky in 2003. She is an Assistant Professor in the Department of Psychology at Indiana University-Purdue University Indianapolis. Her research interests include stereotyping, prejudice, and the impact of such biases on targets. 
MARGO J. MONTEITH received her Ph.D. from the University of Wisconsin in 1991. She is a Professor at Purdue University. Her research interests include stereotyping, prejudice, and prejudice reduction. More generally, she is interested in issues relevant to attitudes, social cognition, and intergroup relations.
STEVEN A. ARTHUR is a doctoral candidate at Purdue University. His research interests include attitudes, stereotyping and prejudice, and intergroup relations.

AMBER BAIN is a student at Northwestern University School of Law. She received her B.A in Psychology from the University of Kentucky in 2003. 